\title{
Microplastic-induced damage in early embryonal development of sea urchin Sphaerechinus granularis
}

Marco Trifuoggi ${ }^{a}$, Giovanni Pagano ${ }^{a}$, Rahime Oral ${ }^{b}$, Dijana Pavičić-Hamer ${ }^{c}$, Petra Burić $^{d}$, Ines Kovačić ${ }^{d}$, Antonietta Siciliano ${ }^{a}$, Maria Toscanesia ${ }^{a}$ Philippe J. Thomas ${ }^{e}$, Luigi Paduanoa, Marco Guidaa, Daniel M. Lyons ${ }^{\text {c,* }}$

a Federico II Naples University, I-80126 Naples, Italy

b Ege University, Faculty of Fisheries, TR-35100 Bornova, İzmir, Turkey

c Center for Marine Research, Ruđer Bošković Institute, HR-52210 Rovinj, Croatia

d J uraj Dobrila University of Pula, HR-52100 Pula, Croatia

e Environment and Climate Change Canada, Science \& Technology Branch, National Wildlife Research Center - Carleton University, Ottawa, Ontario K1A OH3, Canada

* To whom correspondence may be addressed

Daniel Mark Lyons,

Center for Marine Research,

Ruđer Bošković Institute,

HR-52210 Rovinj,

Croatia

Tel.: +385 52804725

Fax: +385 52804780

email: lyons@irb.hr 


\section{Abstract}

Two microplastic sets, polystyrene (PS) and polymethyl methacrylate (PMMA), were tested for adverse effects on early life stages of Sphaerechinus granularis sea urchins. Microparticulate PS (10, 80 and $230 \mu \mathrm{m}$ diameter) and PMMA (10 and $50 \mu \mathrm{m}$ diameter) were tested on developing S. granularis embryos from 10 min post-fertilisation ( $p$-f) to the pluteus larval stage ( $72 \mathrm{~h} \mathrm{p}-\mathrm{f}$ ), at concentrations ranging from 0.1 to $5 \mathrm{mg} \mathrm{L}^{-1}$. Both PS and PMMA exposures resulted in significant concentration-related increase of developmental defects and of microplastic uptake in plutei. Moreover, embryo exposures to PS and PMMA (5 and 50 $\mathrm{mg} \mathrm{L}^{-1}$ ) from $10 \mathrm{~min}$ to $5 \mathrm{~h} \mathrm{p}$-f resulted in a significant increase of cytogenetic abnormalities, expressed as significantly increased mitotic aberrations, while mitotoxicity (as \% embryos lacking active mitoses) was observed in embryos exposed to PS, though not to PMMA. When S. granularis sperm suspensions were exposed for $10 \mathrm{~min}$ to PS or to PMMA (0.1 to $5 \mathrm{mg} \mathrm{L}^{-}$ ${ }^{1}$ ), a significant decrease of fertilisation success was observed following sperm exposure to $0.1 \mathrm{mg} \mathrm{L}^{-1} \mathrm{PS}$, though not to higher PS concentrations nor to PMMA. Sperm pretreatment, however, resulted in significant offspring damage, as excess developmental defects in plutei, both following sperm exposure to PS and PMMA, thus suggesting transmissible damage from sperm pronuclei to the offspring. The overall results point to relevant developmental, cytogenetic and genotoxic effects of PS and PMMA microplastics to S. granularis early life stages, warranting further investigations of other microplastics and other target biota.

Key words:

microplastic; polystyrene; polymethylmethacrylate; developmental defect; genetic damage 


\section{I ntroduction}

Plastics are ubiquitous in every facet of human life and there are few modern products that do not contain plastic components. In recent times the use of plastics, in the form of micro-scale particles, has even extended to personal care products such as creams, scrubs and toothpastes. This latter product represents a potentially direct ingestion route for humans although direct ingestion may also occur through the consumption of foods such as, for example, table salt which has been shown to be contaminated with microplastics (Yang et al., 2015). Thus, the increasing quantities of plastics entering the environment over the past number of decades through wastewater streams or by direct disposal has given increasing cause for concern, not only as an eyesore but due to their potentially deleterious effects on living organisms. The majority of plastics do not readily degrade in the environment but may, though weathering processes, gradually be broken down into increasingly smaller pieces. It is when the size of plastic particles reaches the micro-scale (microplastics, MPs) that their interaction with, and uptake by, organisms may become significant (Wright et al., 2013, and references therein). Further, it should be noted that MPs should not be regarded as a single compound but rather a complex combination of monomers, oligomers and additives such as plasticisers and dyes, and hence discernment of the roles of the individual components on environmental impact is not easily achieved (Rochman et al., 2019). Thus, rather than considering MPs as a single class of materials, it is vital that a broad range of different MPs, taking into consideration size, shape and chemical identity, are investigated in terms of their physicochemical properties in various environmental compartments and their impact in a wide selection of bioassays.

Over the past number of years there has been an increasing quantity of research which has brought attention to MP-induced health effects in a number of aquatic biota, along with concern for adverse health effects in terrestrial biota and humans (reviewed by Andrady, 2011; Alimi et al., 2018; Anbumani and Kakkar, 2018; de Souza Machado et al., 2018; Foley et al., 2018; Gallo et al., 2018). 
However, consensus on the ability of MPs to induce adverse effects has yet to be reached as results remain equivocal since negative effects have not been reported in all bioassay models exposed to MPs, nor widely observed for different MP formulations. For example, several studies reported on a lack of MP-associated adverse effects on biota ranging from urchins to fish (Kaposi et al., 2014; Beiras et al., 2018; Jovanović et al., 2018; Santana et al., 2018; Weber et al., 2018; Beiras and Tato, 2019). However, negative effects were reported for various MPs by Lithner et al. (2012), Straub et al. (2017) and Zhu et al. (2019). Studies in a number of other bioassay models also revealed ingestion, although without considerable toxicity in exposed shrimp (Carreras-Colom et al., 2018; Kokalj et al., 2018; Wang et al., 2019), in fish (Jovanović et al., 2018), in mice (J in et al., 2019) or mussels (Santana et al., 2018). This has recently been reviewed by Foley et al. (2018). On the contrary, adverse effects after MP exposure were reported in several bioassay models, such as multiple biochemical biomarkers and metabolomic profiles in mice, suggesting MPinduced disturbance of energy and lipid metabolism as well as oxidative stress (Deng et al., 2017). Similar findings were reported by Espinosa et al. (2017) who observed the adverse effects of dietary polyvinyl chloride (PVC) MPs on immune status and expression of several stress-related genes in fish Sparus aurata. Leachates from virgin and beached plastic pellets (microPVC), or virgin polystyrene (PS) microbeads affected embryo development and modulated enzymatic activities in mussels (Gandara e Silva et al.; 2017; Magni et al., 2018) while the gut of fish and mice were affected by microbiota dysbiosis and inflammation following exposure to PS MPs (Lithner et al., 2012, J in et al., 2018; 2019; Lei et al., 2018). A report by Martínez-Gómez et al. (2017) provided multi-parameter evidence for the adverse effects of virgin fluorescent PS microspheres and virgin high density polyethylene (PET) fluff both on embryogenesis and fertilisation in the sea urchin Paracentrotus lividus.

Indeed, sea urchins have proven especially valuable in toxicity testing, particularly during the sensitive embryogenesis stage of life, and a range of bioassay protocols have been developed, focusing on testing the effects of xenobiotics or complex mixtures on 
embryogenesis, mitotic activity, sperm fertilisation success, and offspring quality following sperm exposure, and recently reviewed by Pagano et al. (2017). Previous studies reporting on MP-associated effects in sea urchin species such as $P$. lividus or Tripneustes gratilla only found minor, if any, effects on early life stages (Della Torre et al., 2014; Kaposi et al., 2014; Messinetti et al., 2017; Beiras et al., 2018; Gambardella et al., 2018), except for high-dose PVC (Oliviero et al., 2019), and embryotoxicity as reported by Nobre et al. (2015) in sea urchin Lytechinus variegatus.

Even though PS-exposed P. lividus plutei showed ingestion of MPs (Martínez-Gómez et al., 2017), evidence remains scarce for developmental defects in terms of lack of occurrence of skeletal or gut malformations, or developmental arrest at blastula/gastrula stage. Similar results were subsequently noted (Beiras et al., 2018; Beiras and Tato, 2019) for mPET (polyethylene terephthalate) which was tested on $P$. lividus development.

Considering the limited data available on the effects of a narrow selection of MPs on embryogenesis, the widely varying results reported in the literature and the fact that interspecies differences may be significant (Burić et al., 2015), the present study aimed at expanding the knowledge on MP-induced adverse effects by extending the testing of two MPs (PS and polymethyl methacrylate (PMMA)) to fertilisation, embryogenesis and mitotic activity in the sea urchin Sphaerechinus granularis. PS has been selected as it represents one of the most common and widely used polymers and hence is of particular concern as an environmental pollutant while PMMA, though widely used in applications such as paints, cosmetics and detergents in microparticulate form, has not received significant attention to date (European Commission, 2017). Further, PS and PMMA derive from high level hazardous monomers and incorporate reactive functional groups of high concern. Thus it is timely to investigate the behaviour of these microparticles in terms of impact upon biota, and in particular potentially deleterious effects on the sensitive early stages of embryogenesis. 


\section{Materials and methods}

\subsection{Microplastics}

Synthetic, commercially produced PS and PMMA microparticles, with nominal sizes of 10, 80 and $230 \mu \mathrm{m}$ (PS) and 10 and $50 \mu \mathrm{m}$ (PMMA), were acquired from Microbeads SA, Norway as dry solids and used without modification or washing.

\subsection{Sea urchins}

Sea urchins Sphaerechinus granularis were collected off the coast of Rovinj (Croatia, $45^{\circ} 05^{\prime} 08^{\prime \prime} \mathrm{N}, 13^{\circ} 38^{\prime} 22^{\prime \prime} \mathrm{E}$ ) at depths of 5-10 $\mathrm{m}$ by diver. Sperm and eggs were harvested from the gonads, with sperm being held 'dry' at $0{ }^{\circ} \mathrm{C}$ while eggs were kept in FSW until use. The gametes were checked for maturity by visually confirming motile sperm and spherical eggs. The egg suspension was diluted to approximately 1000 eggs $\mathrm{mL}^{-1}$ to which sperm was added at a $10^{5}$ final dilution. At 10 min post-fertilisation $(p-f)$ a $1 \mathrm{~mL}$ aliquot of the zygote suspension was added to $9 \mathrm{~mL}$ FSW containging PS or PMMA suspensions, at concentrations of $0.1,1,5$ and $10 \mathrm{mg} \mathrm{L}^{-1}$, in polystyrene multi-well tissue culture plates. Embryos were thus reared in FSW ( $\mathrm{pH} 8.0-8.2$ ) at $18 \pm 1{ }^{\circ} \mathrm{C}$ for $72 \mathrm{~h}$ until they had reached the pluteus larval stage. All experiments were run with 6 replicates, while non-treated control samples were run trice in 6 replicates.

\subsection{Embryological analysis}

Embryological analysis was performed on living plutei immobilised in $10^{-4} \mathrm{M}$ chromic (III) potassium sulfate dodecahydrate (Carl Roth, Germany) 10 min prior to observation, approximately $72 \mathrm{~h}$ p-f (Pagano et al., 1983). In each replicate the first 100 plutei were scored for the percentages of: normal larvae $(\mathrm{N})$; developmentally delayed larvae $(\mathrm{R}$, size $<1 / 2 \mathrm{~N}$ ); malformed larvae (P1), mostly observed through damaged skeletal differentiation; embryos/larvae unable to attain the pluteus stage - i.e. abnormal blastulae or gastrulae 
(P2); and dead (D) embryos or larvae. Total developmental defects (DD) were considered as the sum of P1 and P2. Reading was carried out blind on randomly-numbered replicates.

\subsection{Cytogenetic analysis}

Cytogenetic analysis was carried out on 30 cleaving $S$. granularis embryos exposed to 5 and $50 \mathrm{mg} \mathrm{L}^{-1} \mathrm{MPs}$ from 10 min p-f. Treatments were run in four replicates, and triplicate controls (each of which also in four replicates) amounting to a total of 12 control cultures. The embryos were fixed in Carnoy's solution (60\% ethanol, 30\% chloroform and $10 \%$ glacial acetic acid) 5 h p-f, and stained by acetic carmine (Pagano et al., 2001). The cytogenetic endpoints allowed both for measurements of mitotic activity and morphological abnormalities. Mitotic activity endpoints included: a) mean number of mitoses per embryo (MPE), and b) percent interphase embryos (IE), i.e. lacking active mitoses. The frequencies of morphologic abnormalities were scored as: a) anaphase bridges; b) lagging chromosomes; c) acentric fragments; d) scattered chromosomes; e) multipolar spindles; f) total mitotic aberrations per embryo; and g) percent embryos having $\geq 1$ mitotic aberration.

\subsection{Sperm bioassays}

To determine any effects on sperm and the resulting offspring after exposure to MP in comparison to MP-exposed embryos, a series of sperm bioassays was carried out. A $50 \mu \mathrm{L}$ aliquot of sperm pellet ('dry' sperm) from each of three males was diluted in $5 \mathrm{~mL} F S W$, and $0.5 \mathrm{~mL}$ of this solution was then added to $4.5 \mathrm{~mL} \mathrm{MP}$ suspensions (final polymer concentrations of $0.1,1$ and $5 \mathrm{mg} \mathrm{L}^{-1}$ ) with periodic and gentle agitation. . After $10 \mathrm{~min}$ exposure to the MPs, $50 \mu \mathrm{L}$ aliquots of these triplicate sperm suspensions were used to inseminate $10 \mathrm{~mL}$ of egg suspensions in polystyrene multi-well tissue culture plates (six replicates), resulting in a 200x dilution of MP-containing sperm suspension. Fertilisation success was measured as percent fertilised eggs (fertilisation rate), i.e. as live cleaving 
embryos 1 to $3 \mathrm{~h}$ p-f. Thereafter, the offspring embryos were cultured up to pluteus stage and scored for developmental defects as described above.

\subsection{Statistical analysis}

Results are given as the mean \pm standard error. Differences between groups were determined through an unpaired two-tailed Student's t-test or with one-way ANOVA and post hoc Dunnett's test after satisfying the requirements of normality of distribution and homogeneity of variance. The variables from cytogenetic analysis were evaluated by $\chi^{2}$ test and Mann-Whitney $U$ test. Differences were considered significant at the $* p<0.05$, $* * \mathrm{p}<0.01$ and $* * * \mathrm{p}<0.001$ levels.

\section{Results}

\subsection{Embryo exposure - Developmental toxicity}

During embryonal development of urchins that were exposed to PS and PMMA MPs a range of developmental morphological defects were noted, including the appearance of normal (N) plutei, as well as malformed (P1) plutei and pre-pluteus embryos in arrested development (P2) (Figure 1). 

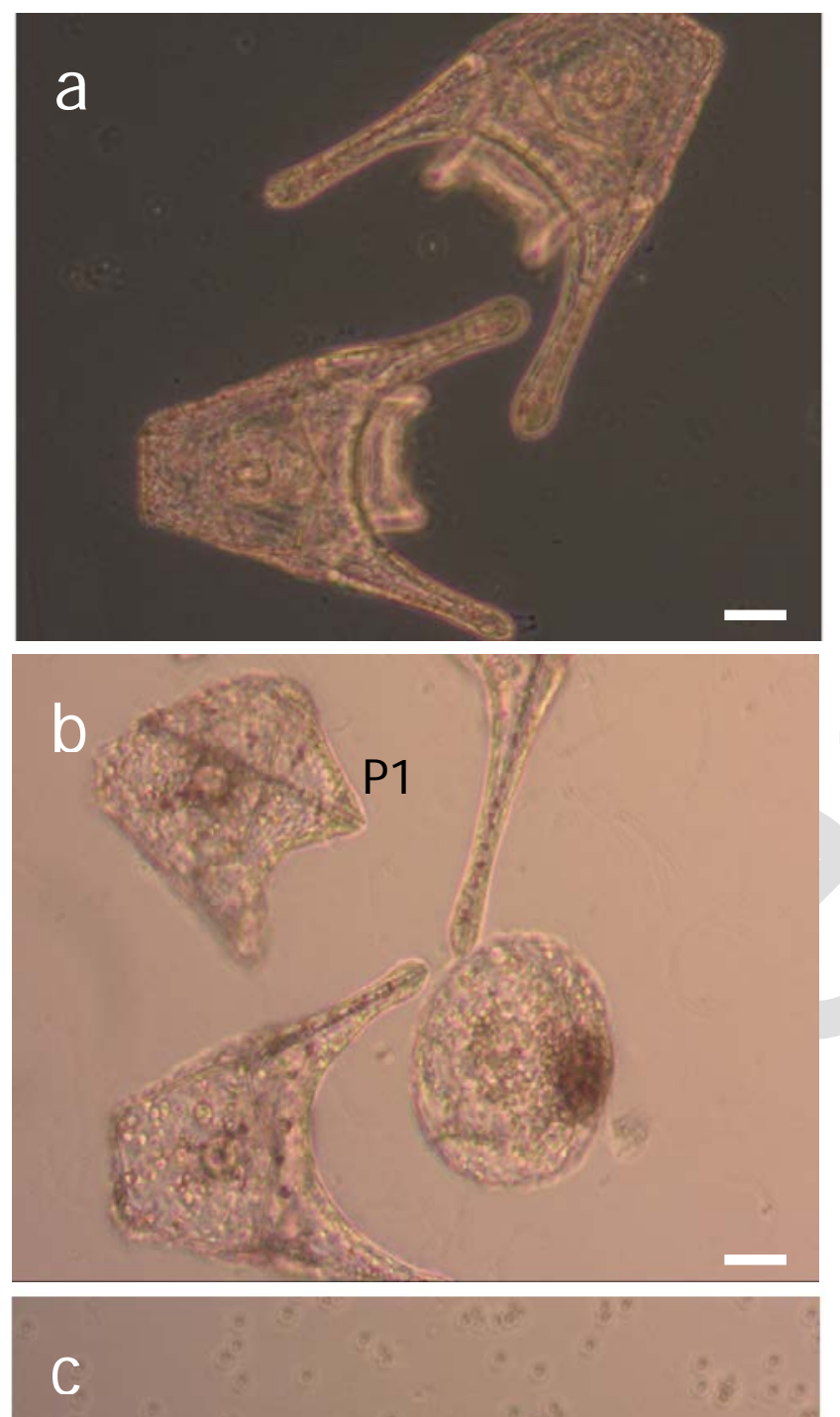

Figure 1. Embryo/larval population of S. granularis including: (a) unexposed normal plutei, (b) MP-exposed malformed (P1) plutei, and (c) arrested pre-pluteus (P2) embryos. Scale bar $=10 \mu \mathrm{m}$ 
S. granularis embryos reared in MP suspensions at concentrations ranging from 0.1 to $1 \mathrm{mg} \mathrm{L}^{-1}$, up to pluteus larval stage ( $72 \mathrm{~h} \mathrm{p}$-f), did not show a significantly greater number of developmental defects (DD) compared to the control plutei as shown in Figure 2.

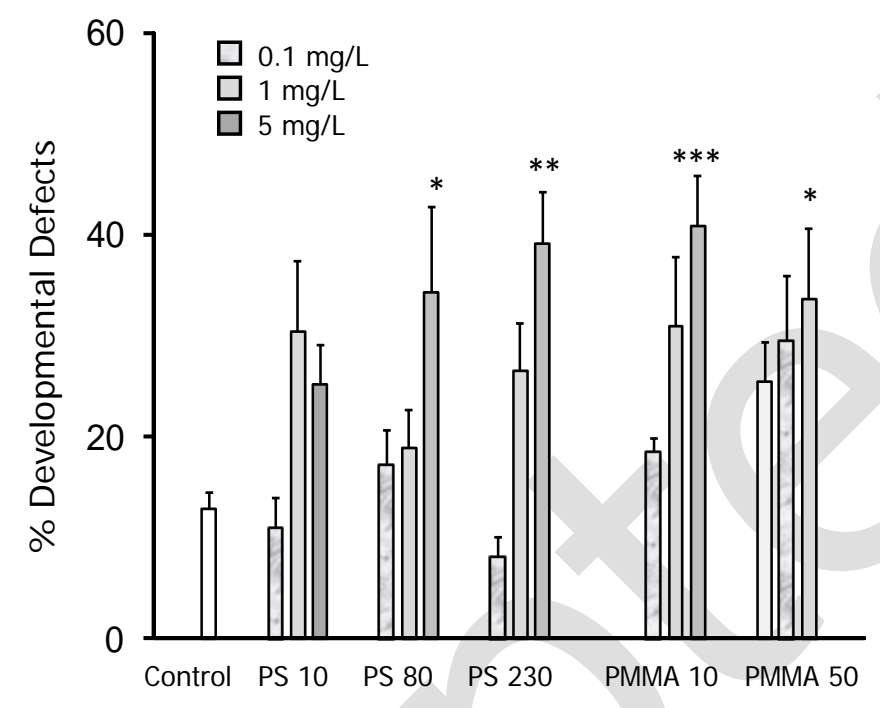

Figure 2. Developmental defects in $S$. granularis embryos/larvae exposed to various concentrations of PS or PMMA microplastics.

However, at the higher concentration of $5 \mathrm{mg} \mathrm{L}^{-1}$ there were significantly increased numbers of malformations, and developmental arrest at blastula-gastrula stage. At the highest concentration, all particle sizes of PS caused a greater number of developmental defects compared to the PMMA microplastics.

\subsection{Embryo exposure - Cytogenetic abnormalities}

As microplastic concentrations of $5 \mathrm{mg} \mathrm{L}^{-1}$ typically showed significantly increased developmental defects with respect to controls, this concentration was tested for inducing cytogenetic damage. A 10-times higher concentration was also tested to determine if there is a concentration-dependent increase in cytogenetic aberrations. Analysis of cleaving $S$. granularis embryos indicated induction of mitotoxicity that was greatest for PS10 and PS80, 
expressed in terms of embryos lacking mitotic features ('Interphase Embryos'), compared to the largest PS (PS230) and PMMA MPs, as shown in Figure 3.

A significant increase of mitotic abnormalities was both observed both in PS- and in PMMA-exposed embryos (Figure 4), expressed as the percentage of embryos with $\geq 1$ mitotic abnormality, indicating MP-induced genetic damage.

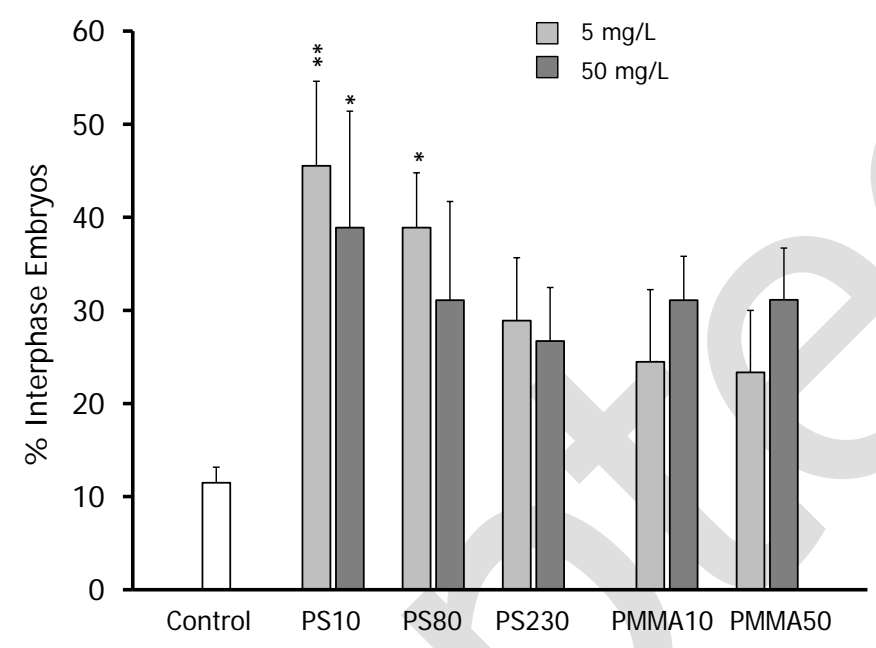

Figure 3. Percent 'Interphase Embryos' lacking mitotic features following exposure to PS or PMMA microplastics.

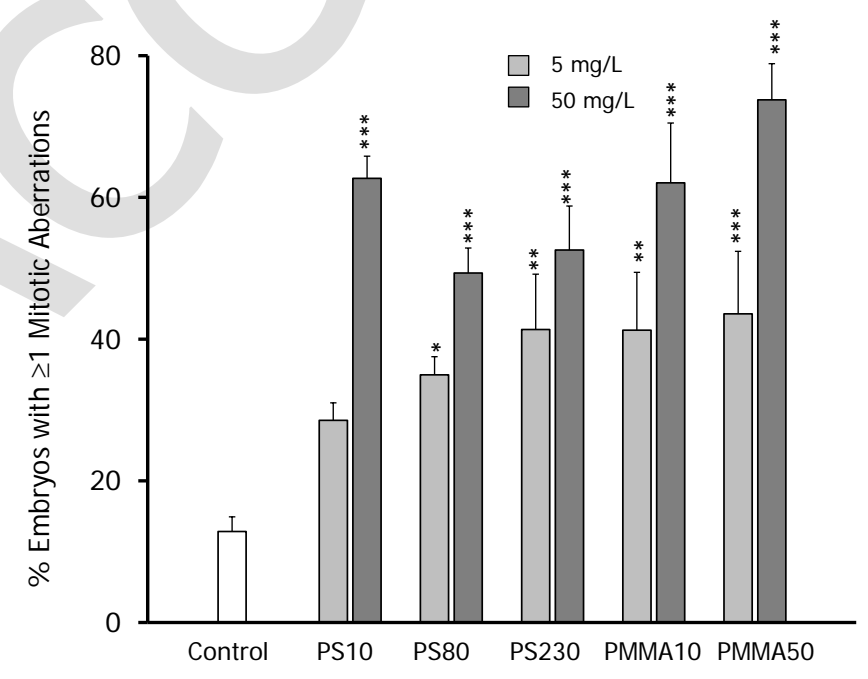

Figure 4. Percentage embryos with $\geq 1$ Mitotic Aberration following exposure to PS or PMMA microplastics. 


\subsection{Sperm exposure - Fertilisation rate and offspring damage}

Exposure of $S$. granularis sperm to PMMA MPs $\left(0.1\right.$ to $\left.5 \mathrm{mg} \mathrm{L}^{-1}\right)$ did not significantly affect their overall fertilisation rate (Figure 5). This was also the case for PS MPs for the higher concentrations of 1 and $5 \mathrm{mg} \mathrm{L}^{-1}$. However, the lowest concentration $(0.1 \mathrm{mg} / \mathrm{L})$, for PS10, PS80 and PS230 resulted in a statistically significant fertilization rate decrease.

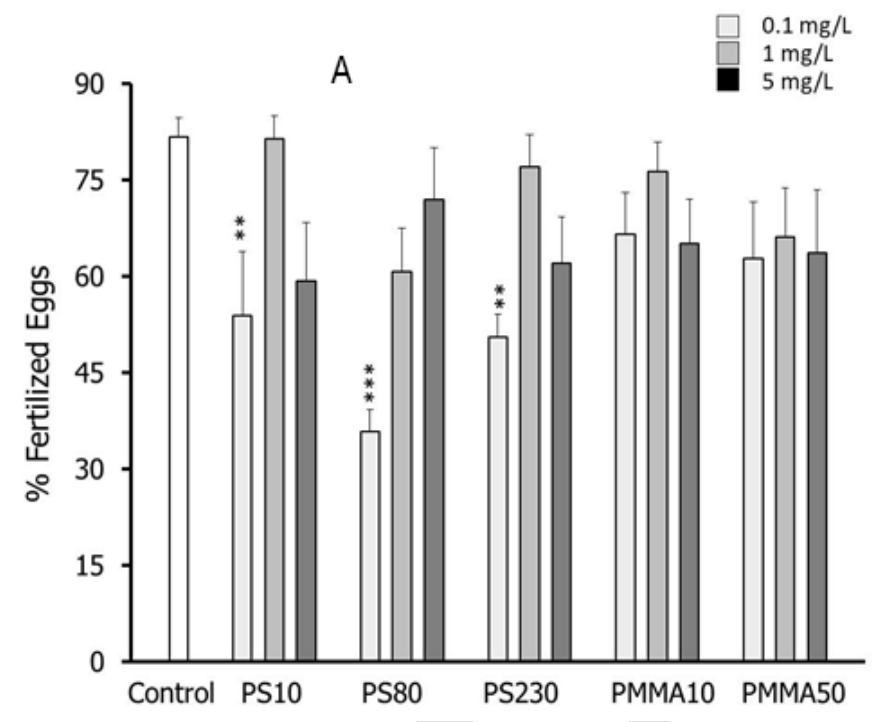

Figure 5. Fertilisation success of S. granularis sperm after exposure to a range of PS and PMMA concentrations and sizes.

In contrast to the overall broad absence of effect on fertilisation success, the offspring of MP-exposed sperm were significantly affected following both PS and PMMA exposures (Figure 6), and in particular after exposure to PMMA50, leading to a significant number of developmental defects encompassing larval malformations (P1) and pre-larval arrest (P2) as shown in Figure 7. Cells showing normal aspects of mitosis and those with cytogenetic aberrations including bridges, lagging chromosomes, and accentric chromosomes after exposure to PMMA50 are also shown in Figure 7. 


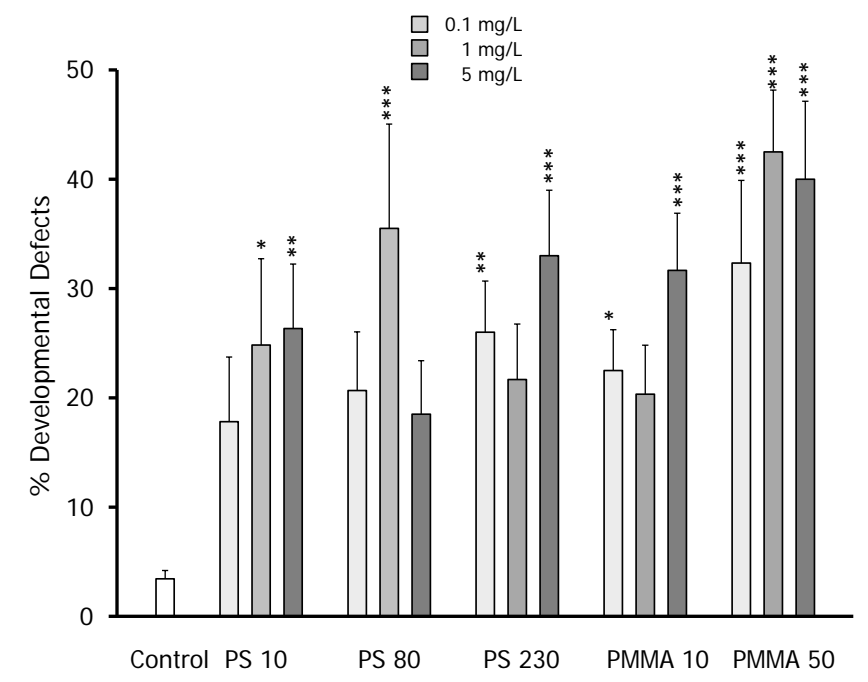

Figure 6. Developmental defects in offspring following sperm exposure to a range of PS and PMMA microplastic sizes and concentrations.
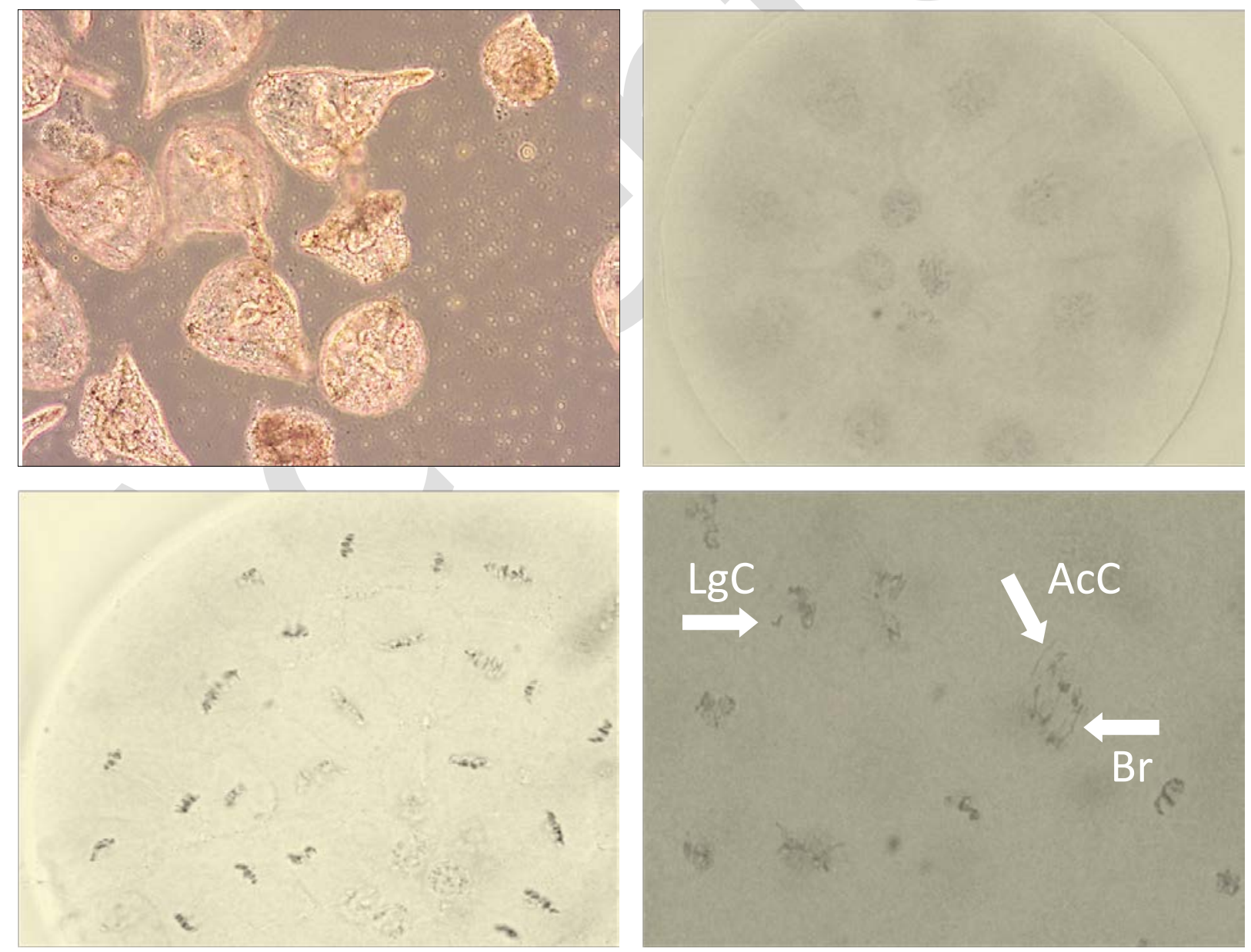

Figure 7. Following sperm exposure to PMMA50, offspring showed a range of aberrations (a) mixed embryo/larval population (b) interphase embryo, (c) normal metaphase and anaphase, and (d) cytogenetic aberrations - bridges (Br), lagging chromosome $(\mathrm{LgC})$ and accentric chromosomes (ACC). 


\section{Discussion}

The present study reports on the clear adverse effects of two spherical MPs, PS and PMMA of different diameters, on the early life stages of the sea urchin $S$. granularis. Three broad MP size classes were selected, i.e. small $(10 \mu \mathrm{m})$, intermediate $(50-80 \mu \mathrm{m})$ and large microparticles $(230 \mu \mathrm{m})$ (in relation to the size of the plutei larvae), since attempting to resolve effects on a finer scale with particles closer in size would likely not yield data with sufficient resolution to clarify the effects on microplastics on embryonal development. Thus, by looking at three relatively different size classes, the focus was placed on giving a clear overview of the size effect of microplastics.

The present study readily found evidence of developmental toxicity in terms of larval malformations and pre-larval arrest in MP-exposed $S$. granularis embryos, indicating the sensitivity of $S$. granularis embryos to these specific MPs. In constrast to other studies where only modest or no toxicity was found, this greater response of $S$. granularis embryos to microplastics compared to $P$. lividus embryos may indicate that the former is more sensitive to such materials. Indeed, this was the case in a previous comparative study of rare earth element toxicity across three sea urchin species (Trifuoggi et al. 2017). Thus, a comparative investigation of MP-induced effects on developing embryos of different species and across a range of materials may provide some useful insight in elucidating this possible difference in species sensitivity.

The physical size of microplastics may play an important role in modulating their uptake, with subsequent disruption of feeding patterns and larval development (Messinetti et al., 2018) although this would become evident only over time scales longer than the $72 \mathrm{~h}$ duration of experiments in the present work. For this reason quantification of uptake is not reported herein as data would be equivocal due to the likelihood that not all plutei had reached the phase of actively feeding by the end of the experiment, i.e. uptake of microplastics by plutei may be a function of development phase where more developed plutei take up microparticles while less developed plutei do not show any uptake. 
The induction of developmental defects in MP-exposed embryos/larvae was not confined to MP gut ingestion as had been previously reported for $P$. lividus sea urchins or Aristeus antennatus shrimps (Beiras et al. 2018; Carreras-Colom et al. 2018). In fact additional and unique evidence for MP-associated adverse effects was provided by cytogenetic analysis of MP-exposed S. granularis embryos which displayed significant inhibition of mitotic activity in PS- though not in PMMA-exposed embryos. However, the embryos showed a significantly increased number of mitotic aberrations, thus pointing to an enhanced frequency of cytogenetic anomalies in embryos reared either in PS or in PMMA microparticle suspensions.

Another finding of this study first showed that a 10-min exposure of S. granularis sperm to a range of concentrations of PS and PMMA MPs failed to affect fertilisation success, with a significant, though unexplained exception for sperm exposure to $0.1 \mathrm{mg} \mathrm{L}^{-1}$ PS for three different microparticle sizes (10,80 and $230 \mu \mathrm{m})$. This unexpected observation is in contrast with a 'canonical' concentration-effect trend and may deserve future investigation.

While it may be concluded that, overall, sperm exposure to either PS or PMMA did not show extensive negative effects on fertilisation success, it is partiularly noteworthy the significant induction of developmental defects and pre-larval arrest in the offspring of both PS- and PMMA-exposed sperm, as first observed in the present study. The induction of offspring damage or mortality following male gametes' exposure to genotoxic agents is not new, both in sea urchin bioassays (reviewed by Pagano et al., 2017) and in other biota such as insects and mammals (reviewed by Sobels 1974; Storey, 2008), and points to transmissible damage to the offspring of sperm pronuclei exposed to genotoxins. Analogous effects were also noted in other studies such as significant reduction in sperm velocity, and larval yield and development in offspring of exposed parents, in oysters chronically exposed to low concentrations of $6 \mu \mathrm{m}$ PS (Sussarellu et al., 2016). Interestingly, those authors noted the presence of molecular signatures of endocrine disruption though no endocrine disruptors were ultimately found in the biological samples. An earlier study in fish also found signals of endocrine disruption after exposure to polyethylene (Rochman et al., 2014). Thus, the 
mechanism of microplastic toxicity might not be related wholly to its physical size but rather in significant part due to its potential to leach other chemicals such as plasticisers whose estrogenicity give rise to endocrine disruption (Kiyama and Wada-Kiyama, 2015). As endocrine disrupting chemicals are known to act at very low concentrations, quantifying them becomes equivocal since concentrations may be very near or below the limit of detection of various instruments. Similar to Sussarellu et al. (2016), in the present work an analysis of the leachate (microplastics aged in artificial seawater $(\mathrm{S} \cdot 38, \mathrm{pH}=8)$ for $72 \mathrm{~h}$ followed by filtration through a $0.22 \mu \mathrm{m}$ regenerated cellulose membrane) by high performance liquid chromatography tandem mass spectrometry (Agilent 1200 HPLC, Agilent 6410 MS) was inconclusive in providing evidence of potential endocrine disrupting molecules. In this work hydrophobic monomers which may potentially leach from the microplastics may be less important as they are relatively volatile (reviewed by Alexander, 1997) and may have short residence time such as the $1-3 \mathrm{~h}$ noted in the case of styrene monomers in lake waters (loss of up to $50 \%$ of $2-10 \mathrm{mg} \mathrm{L}^{-1}$ styrene; Fu and Alexander, 1992). In that laboratory study, while temperature and light parameters for the experiments were not explicitly stated, lake water was noted to have a $\mathrm{pH}$ value of 7.5 which was lower than the $\mathrm{pH}$ of seawater used herein ( $\mathrm{pH}$ 8-8.2). As volatilisation of styrene occurs more slowly at lower $\mathrm{pH}$ (Fu and Alexander, 1992) it may be expected that loss of styrene from seawater may be a more rapid process than in other natural waters such as lake or riverine waters. The present study used a similar range of concentrations $\left(0.1-5 \mathrm{mg} \mathrm{L}^{-1}\right)$ to that study although these materials were in polymer form rather than unpolymerised mers. Thus, the far lower concentrations expected for styrene leached from the microplastics may display significantly different volatilisation kinetics over the $72 \mathrm{~h}$ duration of the embryotoxicity test. However, comprehensive studies on the influence of abiotic parameters such as temperature and light intensity, electrolyte concentration and the presence of natural organic matter on the behaviour of leached monomers in seawater represent important research yet to be carried out. The effect of leachate from $6 \mu \mathrm{m}$ PS was investigated recently by Martínez-Gómez et al. 
(2017). It was found that the leachate from virgin MPs had a greater impact on $P$. lividus embryos than the corresponding leachate from washed particles. A similar result was noted by Nobre et al. (2015) where virgin polyethylene (PE) MPs showed a far greater effect on the urchin Lytechinus variegatus than beached MPs, likely due to leachate from virgin particles being more toxic than that of the corresponding environmentally aged materials. Leachates from micronised plastic (PVC) toys also proved more toxic to developing $P$. lividus embryos than the $\leq 20 \mu \mathrm{m}$ particles themselves (Oliviero et al., 2019) resulting in retarded growth, developmental defects and developmental arrest. The impact of $10 \mu \mathrm{m}$ PS on $P$. lividus juveniles was also reported as delayed growth related to ingestion of dye-containing microparticles thus showing that the particles themselves, due to their physical size, may represent a threat to the early life stages of marine organisms (Messinetti et al., 2018). The effect of leachates from these coloured microparticles were not investigated in detail so any possible effects deriving from additives to the PS remains an interesting aspect to be tested. Sub-micron sized PS particles $(0.1 \mu \mathrm{m})$ also showed interesting effects on $P$. lividus larvae, where statistically significant developmental defects and arrest was not found but an alteration in swimming pattern was noted, with greater swimming speed for the PS treated larvae (Gambardella et al., 2018). In the present work, in broad terms PMMA50 and PS80, as intermediate sized particles, showed similar behaviour, for example in terms of inducing developmental defects where only the $5 \mathrm{mg} \mathrm{L}^{-1}$ treatment for both polymers was significantly different from the control. While size effects, and hence chemical identity effects, were more likely expected for the $10 \mu \mathrm{m}$ particles rather than for the larger particles, the data for the various endpoints for PS10 and PMMA10 are similar (as was the case for the $50-80 \mu \mathrm{m}$ particles), suggesting that the actual primary polymer consituent might not be the most important factor in terms of toxicity. Thus, size may be a more important aspect, possibly as a larger surface area presents greater potential for more rapid leaching of molecules.

Interestingly, unlike PS, reports on the impact of PMMA microparticles are scarce, in spite of the potential for such materials to reach the marine environment due to their 
widespread use either as microparticles added to industrial or consumer products, or as degradation products from weathering of macro-scale PMMA (European Commission, 2017). One of those few reports is based on an investigation of PMMA impact on the freshwater amphipod Gammarus fossarum, with MPs in the size range $32-250 \mu \mathrm{m}$ shown to affect assimilation efficiency and significantly lower weight gain compared to controls indicating MP-induced digestive constraints (Straub et al., 2017). Marine fish have been shown to have ingested PMMA microplastics, with a study on polar cod Boreogadus saida in Arctic waters finding only epoxy-based material and PMMA in the stomach of fish (Kühn et al, 2018). Similarly, in the North Sea, while microplastics in the stomachs of several species of fish was not commonly found, PMMA was noted as the only microplastic present (Hermsen, 2017). Thus, while PMMA remains relatively unstudied, there are increasing reports that this may be a microplastic that is present in the environment in sufficient quantities to warrant investigation of any potentially negative effects on marine biota.

Overall, this study both corroborates some previous evidence for MP-associated embryotoxic-teratogenic effects (Oliviero et al., 2019; Nobre et al., 2015; Pitt et al., 2018; Rainieri et al., 2018; Martins and Guilhermino, 2018) and provides the first evidence for MPinduced genotoxic effects as assessed by cytogenetic analysis and by transmissible damage to the offspring of MP-exposed sperm. The likely analogous effects in other bioassay models may raise some environmental concerns and warrant further investigations.

\section{Acknowledgement}

This work has been supported by the Croatian Science Foundation under project IP-2018-015351. Financial support from Environment and Climate Change Canada is also gratefully acknowledged. Declarations of conflict: none. 


\section{References}

Alexander, M. 1997. Environmental fate and effects of styrene. Crit. Rev. Environ. Sci. Technol. 27, 383-410. doi: 10.1080/10643389709388504.

Alimi, O.S., Farner Budarz, J., Hernandez, L.M., Tufenkji, N. 2018. Microplastics and nanoplastics in aquatic environments: Aggregation, deposition, and enhanced contaminant transport. Environ. Sci. Technol. 52(4), 1704-1724. doi: 10.1021/acs. est. 7b05559.

Anbumani, S., Kakkar, P. 2018. Ecotoxicological effects of microplastics on biota: a review. Environ. Sci. Pollut. Res. Int. 25(15), 14373-14396. doi: 10.1007/s11356-018-1999-x.

Andrady, A.L. 2011. Microplastics in the marine environment. Mar. Pollut. Bull. 62, 15961605. doi: 10.1016/j.marpolbul.2011.05.030.

Beiras, R., Bellas, J., Cachot, J., Cormier, B., Cousin, X., Engwall, M., Gambardella, C., Garaventa, F., Keiter, S., Le Bihanic, F., López-l báñez, S., Piazza, V., Rial, D., Tato, T., Vidal-Liñán, L. 2018a. Ingestion and contact with polyethylene microplastics does not cause acute toxicity on marine zooplankton. J. Hazard. Mater. 360, 452-460. doi: 10.1016/j.jhazmat.2018.07.101.

Beiras, R., Tato, T. 2019. Microplastics do not increase toxicity of a hydrophobic organic chemical to marine plankton. Mar. Pollut. Bull. 138, 58-62. doi: 10.1016/j.marpolbul.2018.11.029.

Burić, P., Jakšić, Ž., Štajner, L., Dutour Sikirić, M., Jurašin, D., Cascio, C., Calzolai, L., Lyons, D.M. 2015. Effect of Silver Nanoparticles on Mediterranean Sea Urchin Embryonal Development is Species Specific and Depends on Moment of First Exposure. Mar. Environ. Res. 111, 50-59. doi: 10.1016/j.marenvres.2015.06.015.

Carreras-Colom, E., Constenla, M., Soler-Membrives, A., Cartes, J.E., Baeza, M., Padrós, F., Carrassón, M. 2018. Spatial occurrence and effects of microplastic ingestion on the deep-water shrimp Aristeus antennatus. Mar. Pollut. Bull. 133, 44-52. doi: 10.1016/j.marpolbul.2018.05.012. 
Della Torre, C., Bergami, E., Salvati, A., Faleri, C., Cirino, P., Dawson, K.A., Corsi I. 2014. Accumulation and embryotoxicity of polystyrene nanoparticles at early stage of development of sea urchin embryos Paracentrotus lividus. Environ. Sci. Technol. 48(20), 12302-12311. doi: 10.1021/es502569w.

Deng, Y., Zhang, Y., Lemos, B., Ren, H. 2017. Tissue accumulation of microplastics in mice and biomarker responses suggest widespread health risks of exposure. Sci. Rep. 7, 46687. doi: 10.1038/srep46687.

de Souza Machado, A.A., Kloas, W., Zarfl, C., Hempel, S., Rillig, M.C. 2018. Microplastics as an emerging threat to terrestrial ecosystems. Glob. Chang. Biol. 24(4), 1405-1416. doi: 10.1111/gcb. 14020.

Espinosa, C., Cuesta, A., Esteban, M.Á. 2017. Effects of dietary polyvinylchloride microparticles on general health, immune status and expression of several genes related to stress in gilthead seabream (Sparus aurata L.). Fish Shellfish Immunol. 68, 251-259. doi: 10.1016/j.fsi.2017.07.006.

European Commission. 2017. Intentionally added microplastics in products. Final Report. 220 pp. https://ec.europa.eu/environment/chemicals/reach/pdf/39168\%20I ntentionally \%20added\%20microplastics\%20-\%20Final\%20report\%2020171020.pdf

Foley, C.J., Feiner, Z.S., Malinich, T.D., Höök, T.O. 2018. A meta-analysis of the effects of exposure to microplastics on fish and aquatic invertebrates. Sci. Total Environ. 631-632, 550-559. doi: 10.1016/j.scitotenv.2018.03.046.

Fu, M.H., Alexander, M. 1992. Biodegradation of styrene in samples of natural environments. Environ. Sci. Technol. 26, 1540-1544. doi: 10.1021/es00032a007.

Gambardella, C., Morgana, S., Bramini, M., Rotini, A., Manfra, L., Migliore, L., Piazza, V., Garaventa, F., Faimali, M. 2018. Ecotoxicological effects of polystyrene microbeads in a battery of marine organisms belonging to different trophic levels. Mar. Environ. Res. 141, 313-321. doi: 10.1016/j.marenvres.2018.09.023. 
Gandara e Silva, P.P., Nobre, C.R., Resaffe, P., Pereira, C.D.S., Gusmão, F. 2016. Leachate from microplastics impairs larval development in brown mussels. Water Res. 106, 364370. doi: 10.1016/j.watres.2016.10.016.

Hermsen, E., Pompe, R., Besseling, E., Koelmans, A.A. 2017. Detection of low numbers of microplastics in North Sea fish using strict quality assurance criteria. Mar. Pollut. Bull. 122, 253-258. doi.org/10.1016/j.marpolbul.2017.06.051

J in, Y., Xia, J., Pan, Z, Yang, J., Wang, W., Fu, Z 2018. Polystyrene microplastics induce microbiota dysbiosis and inflammation in the gut of adult zebrafish. Environ. Pollut. 235, 322-329. doi: 10.1016/j.envpol.2017.12.088.

J in, Y., Lu, L., Tu, W., Luo, T., Fu, Z 2019. Impacts of polystyrene microplastic on the gut barrier, microbiota and metabolism of mice. Sci. Total Environ. 649, 308-317. doi: 10.1016/j.scitotenv.2018.08.353.

Jovanović, B., Gökdağ, K., Güven, O., Emre, Y., Whitley, E.M., Kideys, A.E. 2018. Virgin microplastics are not causing imminent harm to fish after dietary exposure. Mar. Pollut. Bull. 130, 123-131. doi: 10.1016/j.marpolbul.2018.03.016.

Kaposi, K.L., Mos, B., Kelaher, B.P., Dworjanyn, S.A. 2014. Ingestion of microplastic has limited impact on a marine larva. Environ. Sci. Technol. 48(3), 1638-1645. doi: 10.1021/es404295e.

Kiyama, R., Wada-Kiyama, Y. 2015. Estrogenic endocrine disruptors: Molecular mechanisms of action. Environ. Int. 83, 11-40. 10.1016/j.envint.2015.05.012.

Kokalj, A.J., Kunej, U., Skalar, T. 2018. Screening study of four environmentally relevant microplastic pollutants: Uptake and effects on Daphnia magna and Artemia franciscana. Chemosphere 208, 522-529. doi: 10.1016/j.chemosphere.2018.05.172. 
Kühn, S., Schaafsma, F.L., van Werven, B., Flores, H., Bergmann, M., Egelkraut-Holtus, M., Tekman, M.B., van Franeker, J.A. 2018. Plastic ingestion by juvenile polar cod (Boreogadus saida) in the Arctic Ocean. Polar Biol. 41, 12691278. doi: 10.1007/s00300018-2283-8.

Lei, L., Wu, S., Lu, S., Liu, M., Song, Y., Fu, Z., Shi, H., Raley-Susman, K.M., He, D. 2018. Microplastic particles cause intestinal damage and other adverse effects in zebrafish Danio rerio and nematode Caenorhabditis elegans. Sci. Total Environ. 619-620, 1-8. doi: 10.1016/j.scitotenv.2017.11.103.

Lithner, D., Nordensvan, I., Dave, G. 2012. Comparative acute toxicity of leachates from plastic products made of polypropylene, polyethylene, PVC, acrylonitrile-butadienestyrene, and epoxy to Daphnia magna. Environ. Sci. Pollut. Res. Int. 19, 1763-1772. doi: 10.1007/s11356-011-0663-5.

Magni, S., Gagné, F., André, C., Della Torre, C., Auclair, J., Hanana, H., Parenti, C.C., Bonasoro, F., Binelli, A. 2018. Evaluation of uptake and chronic toxicity of virgin polystyrene microbeads in freshwater zebra mussel Dreissena polymorpha (Mollusca: Bivalvia). Sci. Total Environ. 631-632, 778-788. doi: 10.1016/j.scitotenv.2018.03.075.

Martínez-Gómez, C., León, V.M., Calles, S., Gomáriz-Olcina, M., Vethaak, A.D. 2017. The adverse effects of virgin microplastics on the fertilization and larval development of sea urchins. Mar. Environ. Res. 130, 69-76. doi: 10.1016/j.marenvres.2017.06.016.

Martins A., Guilhermino, L. 2018. Transgenerational effects and recovery of microplastics exposure in model populations of the freshwater cladoceran Daphnia magna Straus. Sci. Total Environ. 631-632, 421-428. doi: 10.1016/j.scitotenv.2018.03.054.

Messinetti, S., Mercurio, S., Parolini, M., Sugni, M., Pennati, R. 2018. Effects of polystyrene microplastics on early stages of two marine invertebrates with different feeding strategies. Environ. Pollut. 237, 1080-1087. doi: 10.1016/j.envpol.2017.11.030. 
Nobre, C.R., Santana, M.F.M., Maluf, A., Cortez, F.S., Cesar, A., Pereira, C.D.S., Turra, A. 2015. Assessment of microplastic toxicity to embryonic development of the sea urchin Lytechinus variegatus (Echinodermata: Echinoidea). Mar. Pollut. Bull. 92, 99-104. doi: 10.1016/j.marpolbul.2014.12.050.

Oliviero, M., Tato, T., Schiavo, S., Fernández, V., Manzo, S., Beiras, R. 2019. Leachates of micronized plastic toys provoke embryotoxic effects upon sea urchin Paracentrotus lividus. Environ. Pollut. 247, 706-715. doi: 10.1016/j.envpol.2019.01.098.

Pagano, G., Esposito, A., Bove, P., de Angelis, M., Rota, A., Giordano, G.G. 1983. The effects of hexavalent and trivalent chromium on fertilization and development in sea urchins. Environ. Res. 30, 442-452. https://doi.org/10.1016/0013-9351(83)90230-X.

Pagano, G., Korkina, L.G., Iaccarino, M., De Biase, A., Deeva, I.B., Doronin, Y.K., Guida, M., Melluso, G., Meriç, S., Oral, R., Trieff, N.M., Warnau, M. 2001. Developmental, cytogenetic and biochemical effects of spiked or environmentally polluted sediments in sea urchin bioassays. In: Garrigues, P., Walker, C.H., Barth, H. (Eds.) Biomarkers in Marine Ecosystems: A Practical Approach. Elsevier, Amsterdam, pp. 85-129.

Pagano, G., Guida, M., Trifuoggi, M., Thomas, P.J., Palumbo, A., Romano, G., Oral, R. 2017. Sea urchin bioassays in toxicity testing: I. Inorganics, organics, complex mixtures and natural products. Expert Opin. Environ. Biol. 6, 1. https://doi.org/10.4172/23259655.1000142.

Pitt, J.A., Kozal, J.S., Jayasundara, N., Massarsky, A., Trevisan, R., Geitner, N., Wiesner, M., Levin, E.D., Di Giulio, R.T. 2018. Uptake, tissue distribution, and toxicity of polystyrene nanoparticles in developing zebrafish (Danio rerio). Aquat. Toxicol. 194, 185-194. doi: 10.1016/j.aquatox.2017.11.017.

Rainieri, S., Conlledo, N., Larsen, B.K., Granby, K., Barranco, A. 2018. Combined effects of microplastics and chemical contaminants on the organ toxicity of zebrafish (Danio rerio). Environ Res. 162, 135-143. doi: 10.1016/j.envres.2017.12.019. 
Rochman, C.M., Kurobe, T., Flores, I., Teh, S.J. 2014. Early warning signs of endocrine disruption in adult fish from the ingestion of polyethylene with and without sorbed chemical pollutants from the marine environment. Sci. Total Environ. 493, 656-661. doi: 10.1016/j.scitotenv.2014.06.051

Rochman, C.M., Brookson, C., Bikker, J., Djuric, N., Earn, A., Bucci, K., Athey, S., Huntington, A., Mcl lwraith, H., Munno, K., De Frond, H., Kolomijeca, A., Erdle, L., Grbic, J., Bayoumi, M., Borrelle, SB., Wu, T., Santoro, S., Werbowsk, LM., Zhu, X., Giles, RK., Hamilton, BM., Thaysen, C., Kaura, A., Klasios, N., Ead, L., Kim, J., Sherlock, C., Ho, A., Hung, C. 2019. Rethinking microplastics as a diverse contaminant suite. Environ. Toxicol. Chem. 38, 703-711. doi: 10.1002/etc.4371.

Santana, M.F.M., Moreira, F.T., Pereira, C.D.S., Abessa, D.M.S., Turra, A. 2018. Continuous exposure to microplastics does not cause physiological effects in the cultivated mussel Perna perna. Arch. Environ. Contam. Toxicol. 74, 594-604. doi: 10.1007/s00244-0180504-3.

Sobels, F.H. 1974. The advantages of drosophila for mutation studies. Mutat. Res. 26, 277284.

Storey, B.T. 2008. Mammalian sperm metabolism: oxygen and sugar, friend and foe. Int. J. Dev. Biol. 52, 427-437. doi: 10.1387/ijdb.072522bs.

Straub, S., Hirsch PE., Burkhardt-Holm, P. 2017. Biodegradable and petroleum-based microplastics do not differ in their ingestion and excretion but in their biological effects in a freshwater invertebrate Gammarus fossarum. Int. J. Environ. Res. Public Health. 14(7), pii: E774. doi: 10.3390/ijerph14070774.

Sussarellu, R., Suquet, M., Thomas, Y., Lambert, C., Fabioux, C., Pernet, M.E.J ., Le Goïc, N., Quillien, V., Mingant, C., Epelboin, Y., Corporeau, C., Guyomarch, J., Robbens, J., PaulPont, I., Soudant, P., Huvet, A. 2016. Oyster reproduction is affected by exposure to polystyrene microplastics. PNAS 113(9), 2430-2435. doi: 10.1073/pnas.1519019113 
Trifuoggi, M., Pagano, G., Guida, M., Palumbo, A., Siciliano, A., Gravina, M., Lyons, D.M., Burić, P., Levak, M., Thomas, P.J., Giarra, A., Oral, R. 2017. Comparative toxicity of seven rare earth elements in sea urchin early life stages. Environ. Sci. Poll. Res. 24, 20803-20810. doi:10.1007/s11356-017-9658-1.

Wang, Y., Zhang, D., Zhang, M., Mu, J., Ding, G., Mao, Z., Cao, Y., J in, F., Cong, Y., Wang, L., Zhang, W., Wang, J. 2019. Effects of ingested polystyrene microplastics on brine shrimp, Artemia parthenogenetica. Environ. Pollut. 244, 715-722. doi: 10.1016/j.envpol.2018.10.024.

Weber, A., Scherer, C., Brennholt, N., Reifferscheid, G., Wagner, M. 2018. PET microplastics do not negatively affect the survival, development, metabolism and feeding activity of the freshwater invertebrate Gammarus pulex. Environ. Pollut. 234, 181-189. doi: 10.1016/j.envpol.2017.11.014.

Wright, S.L., Thompson, R.C., Galloway, T.S. 2013. The physical impacts of microplastics on marine organisms: a review. Environ. Pollut. 178, 483-492. doi: 10.1073/pnas. 1519019113

Yang, D., Shi, H., Li, L., Li, J., Jabeen, K., Kolandhasamy, P. 2015. Microplastic pollution in table salts from China. Environ. Sci. Technol. 49(22), 13622-13627. doi: 10.1021/acs.est. 5b03163.

Yu, P., Liu, Z, Wu, D., Chen, M., Lv, W., Zhao, Y. 2018. Accumulation of polystyrene microplastics in juvenile Eriocheir sinensis and oxidative stress effects in the liver. Aquat. Toxicol. 200, 28-36. doi: 10.1016/j.aquatox.2018.04.015.

Zhu, Z.L., Wang, S.C., Zhao, F.F., Wang, S.G., Liu, F.F., Liu, G.Z 2019. Joint toxicity of microplastics with triclosan to marine microalgae Skeletonema costatum. Environ. Pollut. 246, 509-517. doi: 10.1016/j.envpol.2018.12.044. 